\title{
Ценности семейного воспитания в контексте российского законодательства (историко-педагогический аспект)
}

Л. О. ВолодинА - профессор кафедры психологии и педагогики, заместитель директора института истории и филологии Вологодского государственного университета, доктор педагогических наук, доцент

\section{Р е фер ат}

Статья посвящена проблеме ценностей семейного воспитания в контексте российского законодательства, исторических условий их формирования как фактора позитивного развития государства в период с Древней Руси до второй половины XIX в., отражающего национальные особенности становления семейного права, его традиций. Ее содержание нацелено на осознание обществом роли и степени влияния государства на создание семьи как социального института, функции которого определяются задачами продолжения рода и воспитания достойных граждан своего отечества. Автором проводится главная мысль о том, что ценности семейной жизни, семейного воспитания и нормы семейного права представляют собой взаимодополняющие категории.

В качестве методов исследования используются структурный анализ текстов законодательных актов, источников и научных исследований по этнической истории и законодательству, содержащих нормы российского законодательства, анализ нормативно-правовых актов в области семейной политики и семейного воспитания. Это позволяет выявить, изучить и интерпретировать данные о сущности и содержании ценностей семейного воспитания в структуре семейного права в разные исторические периоды.

Текст обращен к широкому кругу читателей, интересующихся историей своей страны. Он может быть использован при подготовке историко-педагогических трудов, освещающих проблему семейного воспитания и ценностей как его основы. Содержащиеся в статье исторические факты будут интересными для специалистов, занимающихся разработкой законодательно-нормативных актов, регулирующих вопросы брачно-семейных отношений.

Ключевые слова: ценностные основания семейной жизни; ценности семейного воспитания; нормы и традиции семейного воспитания; брачно-семейное поведение; российское законодательство в сфере семейного воспитания; анализ законодательных документов в области семейных отношений.

13.00.01 - Общая педагогика, история педагогики и образования 


\title{
The values of family education in the context of Russian legislation (historical and pedagogical aspect)
}

\author{
L. O. VOLODINA - Professor of the Department of Psychology and Pedagogy, \\ Deputy Director of the Institute of History and Philology of the Vologda State \\ University, Dsc. in Pedagogics, Associate Professor
}

\begin{abstract}
The article is devoted to the problem of the values of family education in the context of Russian legislation, the historical conditions of their formation as a factor in the positive development of the state from Ancient Russia to the second half of the 19th century, reflecting the national characteristics of the formation of family law and its traditions. Its content is aimed at public awareness of the role and degree of influence of the state on the creation of the family as a social institution, whose functions are determined by the tasks of procreation and the education of worthy citizens of their country. The author holds the main idea that the values of family life, family upbringing and the norms of family law are complementary categories.

As research methods a structural analysis of texts of legislative acts sources and scientific research on ethnic history and legislation containing the norms of Russian legislation, analysis of regulatory legal acts in the field of family policy and family education is used. This allows you to identify, study and interpret data on the nature and content of the values of family education in the structure of family law in different historical periods. The text is addressed to a wide circle of readers interested in the history of their country. It can be used in the preparation of historical and pedagogical works, highlighting the problem of family education and values as its basis. The historical facts contained in the article will be interesting for specialists involved in the development of legislative and regulatory acts governing marriage and family relations.

Ke y words: value foundations of family life; values of family education; norms and traditions of family education; marital and family behavior; Russian legislation in the field of family education; analysis of legislative documents in the field of family relations.
\end{abstract}

13.00.01 - General pedagogy, history of pedagogy and education

Современная политика Российской Федерации в сфере брачно-семейных отношений направлена на укрепление семьи как социального института. В то же время в ситуации развития индустриального общества широкое распространение получают индивидуалистически ориентированные системы ценностей с таким приоритетом, как свобода выбора брачного партнера и форм совместной жизни. Значительное увеличение степени свободы в выборе индивидуальных целей и средств их достижения стимулировало появление следующих явлений в области семейной жизни: переход к индивидуалистически ориентированной зрелой паре с одним или двумя детьми от детоцентристской модели семьи; переход к плюралистическим моделям семьи, юридически не оформленным, от унифицированной модели. В стране тенденция снижения показателей численного воспроизводства населения находится на одном уровне с тенденцией снижения показателей брачности. Наблюдается трансформация семейных ценностей, выражающаяся в модификации представлений о взаимоотношениях поко- лений в семье и утрате родовых идентификаций, смене полоролевых позиций членов семьи [2, с. 331].

В силу этих обстоятельств представляется целесообразным научное обоснование вопроса о роли исторически сложившихся традиций семейного воспитания как в общем контексте национальной политики государства, так и в сфере брачно-семейного поведения.

В отношении понятия «брачно-семейное поведение», обоснованного современными социологами и юристами, нами фиксируется ряд его составляющих, значимых для рассмотрения проблемы ценностного потенциала семейного воспитания [2, с. 145].

Во-первых, данная категория сопряжена с такими ее разновидностями, как супружество, родительство, родство, предопределяющими направленность изучения. Объектом государственного интереса являются те сферы, юридическое нормирование которых отражает понимание государством ценностной основы семейной жизни. В процессе дальнейшего анализа законодательных документов внимание будет обращено 
на ценностные аспекты регулирования государством брачно-семейного поведения. Во-вторых, при описании механизма этого взаимодействия используется термин «поведенческая парадигма», подразумевающий следующее содержание: нормы-ценности семейной жизни, сформулированные государством, становятся впоследствии нормами-ценностями самой семьи, определяя ее поведение.

Процесс институализации семьи на Руси шел практически одновременно с процессом институализации таких социальных организаций, как государство и церковь. Эта точка зрения подтверждается следующим изречением В. Я. Стоюнина: «В древности семья не составляла отдельной независимой единицы» [12, с. 1].

Анализ содержания исторических источников, прежде всего законодательных актов, наглядно показывает стремление государства к построению юридических отношений с семьей.

Конструирование и реализацию правового регулирования брачно-семейного поведения на основе ценностей семейной жизни и семейного воспитания исследователи относят к началу XII в. - моменту формирования Киевской Руси. Это было сопряжено с принятием христианства под непосредственным влиянием византийской культуры.

Обращение законодателей к культуре Византийской империи было продиктовано ее способностью дать продуктивные образцы семейного быта. В ст. 9 Синоидальной редакции Церковного устава князя Владимира Святославовича за церковью были закреплены судебные полномочия по следующим семейным делам: «роспуты (развод), смилное (любовная связь), пря между мужем и женой о животе (споры между мужем и женой об имуществе)» [8, с. 149].

Государственное законодательство в области семейного права с самого начала развивалось в сотрудничестве с русской церковью. Государство и церковь совместно создавали юридические документы, в которых закреплялось понимание института семьи и брака согласно христианской модели, обеспечивающей физическое и духовное выживание рода.

В компетенции законодателя находился ряд проблем, связанных с актом бракосочетания и последующим обоснованием системы действий, направленных на сохранение статуса брака (формы, условия заключения и расторжения), уточнение статусно-ролевых позиций членов семьи, установление порядка имущественных отношений. Раскроем их ценностную составляющую, позволяющую судить о нравственном самосознании законодателя в данной сфере, с опорой на проведенное нами историко-педагогическое исследование [2].

Главным основанием семейной жизни считался христианский брак. Понимание смысла христианской формы бракосочетания было раскрыто в работе русского правоведа А. С. Павлова. Со ссылкой на 49 главу Кормчей книги он объясняет читателям «существенное свойство брака» с четырех позиций. Прежде всего, его физиологическая составляющая (половое влечение) ведет к осмыслению брака как «естественного элемента различения полов», установленного самой природой для продолжения «по божественному плану миротворения» своего рода. С другой стороны, это этический союз, предполагающий «полное и неразрывное общение всех жизненных отношений между супругами» [5, с. 226-229]. Далее, юридически это союз, основанный «на взаимном желании, воле» (следовательно, договоре) вступить «в постоянное половое сожитие». И наконец, это церковный союз, который являет собой таинство брака [6, с. 230].

Такое понимание природы брака находит подтверждение в законодательстве Древнерусского государства и развивается в дальнейшем в российском законодательстве с утверждением главных христианских принципов семейной жизни - разнополого союза и моногамии. Другие варианты сожительства в христианстве браком не считались и не имели законного характера.

C утверждением принципа разнополого союза «как мужеви и жене сочетание, событие во всей жизни, божественная и человеческая правды общения» [9, с. 204] закреплялись понятия «муж», «жена», каждое из которых несло в себе ценностное начало совместной жизни. Если категория «муж» изначально связывалась с термином «свободный» и использовалась применительно к свободным людям внутри социальной группы, то в законодательной практике данное слово стало употребляться в связи с понятием «жена». Обратившись к древнерусским юридическим актам, в частности Краткой редакции Устава князя Ярослава (ст. 10-11), находим тому подтверждение: «Аже жене лихи недуг болит... про то ее не пустити. Тако же и жене нельзя пустити мужа» [8, с. 163-164].

Принцип моногамии вводил в аксиологическую сферу семейной жизни такие цен- 
ностные категории, как целомудрие, супружество, кровное свойство.

Целомудрию в законодательных актах уделялось большое внимание, особенно в ранние годы становления христианства на Руси. Впервые появившись в Краткой редакции Устава князя Ярослава, мысль о необходимости сохранения целомудрия получила отражение в 8 статьях из 38 ее составлявших и была интерпретирована как запрет на внебрачную связь (прелюбодеяние). Воздействие на нарушителя осуществлялось посредством санкции имущественного характера в виде денежного штрафа [8, c. 168-170].

Другой важнейшей ценностью семейной жизни законодатель называл супружество, рассматривая его как обязанность совместной жизни, данную Богом «на постоянно половое сожитие». Термин «супруги» встречается в более поздних законодательных актах (периода Российской империи), но значимость супружества подразумевается в настойчивом проведении идеи о нерасторжимости брака. Термин «супруги» используется в отношении таких юридических принципов, как установление единства фамилии семьи, определение ее социального статуса и местожительства. Это требовало выработки норм поведения в условиях сожительства. Сговорчивость и гибкость, прощение и взаимопомощь, покорность, желание учиться друг у друга, искусство слушать другого, честное и откровенное общение, верность в горе и радости - вот нравственные составляющие данной духовной категории. Несмотря на то, что соблюдение закона совместного сожительства как нормы семейной жизни относится лишь К XVI в. (гл. 20 Стоглава 1551 г.) [9, с. 228], само обращение к ценности «супружество» - основе брака несет в себе представление нравственного характера. Пресечение повторных браков с вытекающим отсюда понятием «незаконнорожденный», ущемление интересов незаконнорожденного в области имущественного наследования, сложный по своей структуре порядок расторжения брака, высокие штрафные санкции в случае нарушения законодательных требований - все это подтверждает стремление законодателя достигнуть прочности семейных отношений. Так, примером может послужить принятие государственной властью постановлений об оставлении без удовлетворения исков от незаконнорожденных детей после смерти родителей в отношении их имущества, дабы «не подавать силы опасному примеру» [7, т. XX, № 14778; 8, с. 168].
Объединение мужа и жены понятием «супружество» (союз членов двух родов) повлекло за собой расширение юридической терминологии за счет введения категории «кровное свойство», приравниваемой по своей сущности к кровному родству с вытекающим отсюда следствием запрета на брак между свойственниками. В числе последних называются тесть, зять, свекровь, невестка, отчим, падчерица [8, с. 169].

По церковному учению брак прекращался только физической смертью одного из супругов, исключая все болезни, кроме «заразительной» (проказы), чем еще раз подтверждается суть супружеской жизни как готовности поддержать супруга ценой собственного благополучия. В судопроизводстве брак подлежал расторжению из-за неспособности мужа к супружеской жизни и неспособности жены к деторождению [8, с. 168-169], и признание этих условий вводит в ранг ценностных основ семейной жизни понятие «ребенок», рассматривая его как главное предназначение семьи.

В условиях становления православной культуры возникала необходимость трансляции ее идей, что представлялось возможным через наиболее значимые для ребенка образы отца и матери. С этой целью церковью использовался обряд крещения, превозносивший духовное рождение с привлечением крестных родителей - восприемников от купели - и возложением на них обязанности «блюсти за религиознонравственным ростом новокрещенного» [6, с. 222]. Если сам акт крещения являлся основанием приобретения «общей церковной правоспособности», то восприемники (крестные) выступали как поручившиеся за «религиозно-нравственную зрелость» крещаемого [6, с. 222].

Право на вступление в брак конкретизировалось и с учетом физических качеств лиц. В более ранних законодательных актах (периода Древней Руси) девушкам разрешалось вступать в брак с двенадцатилетнего возраста, юношам - с пятнадцатилетнего, что объяснялось влиянием норм византийского права. Позитивные перемены в этом вопросе произошли в законодательстве Петра І. Он предпринял попытку обоснования повышения нижней возрастной границы (18 лет для мужчины, 16 лет для женщины). В Указе о порядке наследования в движимых и недвижимых имениях от 23 марта 1714 г. говорилось о необходимости умственной зрелости, параметрами которой выступали навыки ведения домашнего хозяйства и воспитания детей, возможность деторожде- 
ния (не старше 80 лет для мужчины и 60 лет для женщины) [10, с. 295-299]. Власть стремилась также привлечь к государственной службе образованных молодых людей, не обремененных семейной жизнью.

Таким образом, с понятием о брачном возрасте в сферу семейного воспитания входит такая категория ценностного содержания, как совершеннолетие (совершенные лета). Смысл и значимость ее заключаются в осознанной ответственности человека перед Богом и государством за свои поступки и способности к самостоятельной жизни с последующим прекращением или ограничением (при поступлении на службу, замужестве) родительской власти.

Эмансипации детей придавали большое значение. Об этом свидетельствует сохранявшийся в течение нескольких столетий обряд «посаженья на коня», носивший характер возрастной инициации. Выполнение определенных действий имело целью фиксацию перехода человека из статуса юноши в статус мужчины с наложением на него прав и обязанностей по обеспечению своей жизни и признанием за ним «достоинства полноправного члена семьи» [1, с. 540]. В ст. 99 Пространной редакции Русской Правды впервые говорится о понятии «совершеннолетие», прекращении опеки, когда «опекаемые будут сами собой печаловати» [8, с. 71]. Возраст зрелости ранние источники не устанавливают. В более позднее время он приравнивается к брачному возрасту.

Важным условием свершения брака признавалось волеизъявление брачующихся. Древнерусские законы ограждали детей от произвола родителей в вопросах брака. Так, согласно ст. 24 Устава Ярослава Мудрого, родители, виновные в принуждении детей к браку или удерживающие их от брака, подвергались суду [8, с. 169]. Следовательно, можно говорить о понимании законодателем значимости такой духовной ценности, как любовь, представляющей собой исходное положение прочного брака. В то же время браки не свершались без родительского благословения, которое всегда расценивалось как фактор благополучия человека, стремящегося к самостоятельной жизни.

Позиция законодателя о необходимости свободного выбора вступающих в брак сохранялась на протяжении нескольких веков до периода образования централизованного государства в XVI в. Ее пересмотр был продиктован сложившимися новыми социально-политическими условиями. Последующая реформация семейного за- конодательства в царствование Петра I, коснувшись проблемы волеизъявления, ставила задачу примирения двух противоположностей - «свободного произволения брачующихся» и «воли родителей» [1, с. 491]. Несмотря на то, что положение Указа об отмене рядных и сговорных записей 1702 г. о «не принуждении к брачному сочетанию» под угрозой «тяжкого штрафования» казалось неправомерным из-за многовековых традиций «старорусской семейной власти» и имело силу только в среде «знатных персон» [1, с. 492], само обращение к мнению члена семьи говорило об усилении индивидуализации его прав [7, т. IV].

Рассматривая вопрос о ценностных основаниях семейной жизни, следует обратить внимание на решение проблемы имущественных отношений как экономической основы брачного союза с участием двух родов и связанного с этим права наследования по закону и по завещанию. Данная область юрисдикции под влиянием устойчивых элементов языческого сознания имела отличия от европейского семейного права, что оказало влияние на ценностный мир русской семьи. Так, признание в ст. 94 Пространной редакции Русской Правды за замужней женщиной большей самостоятельности в имущественном отношении свидетельствовало об изначально высоком статусе жены [8, с. 70]. Утверждение принципа раздельности прав на имущество только в XVIII в. по указу о праве жены распоряжаться своей недвижимостью по своему усмотрению 1753 г. [5, c. 55] с преобладанием до этого принципа общности обнаруживает приоритет равноправия супружеских отношений. Позднее время введения принципа раздельности М. Ф. Владимирский-Буданов объясняет тем, что это «начало мертвое», «противоречащее древнему справедливому понятию о браке» [1, с. 532]. О приоритете равноправия свидетельствуют такие постановления, как решение о равенстве условий при разводе, равнодолевое наследование имущества отца сыновьями с возложенными на них отцовскими обязательствами равнозначных налоговых выплат. Преимущество младшего сына перед старшими братьями в наследовании двора отца возлагало на него обязанность содержания родителей до их смерти. Свидетельством авторитета материнской власти было то обстоятельство, что, согласно ст. 103, 106 Пространной редакции Русской Правды, в ситуации выбора наследника она руководствовалась добрым к ней отношением: «а матери, кото- 
рым сын добр... тому же даст свое, а дочери может дати, кто ю кормит» [8, с. 71].

Другим отличительным принципом русского права был принцип, согласно которому при отсутствии завещания имущество по закону переходило всем сыновьям в равных долях. Петр I в русле западноевропейской традиции указом о единонаследии предпринял попытку ввести принцип первородства (майората). Отрицательные последствия приятия данного закона - ссоры, ненависть, смертоубийства - привели к его отмене в 1731 г. указом Анны Иоанновны «как противоречащего стабильному функционированию русской семьи по традиции обычного права» [4, с. 412].

Следует выделить и другие постановления законодателя в сфере имущественных отношений, прежде всего те, что касаются определения круга наследников. Урегулирование вопроса о наследниках по завещанию ставило также и задачи нравственного характера. Заметное расширение круга допускаемых к наследованию лиц в XVI-XVII вв. по Судебнику Ивана Васильевича имело целью формирование «безграничного понятия родства» [1, с. 580], что отвечало политике централизации власти. Уменьшение численного состава семьи в XVIII в. влекло за собой, с одной стороны, повышение социальной мобильности взрослых женатых детей и последующее возникновение обособленных семейных хозяйств, с другой - смещение центра тяжести в семейно-родственных отношениях от родственных связей между братьями к родственным связям между родителями и детьми, что свидетельствовало о зарождении ценности индивидуальной личности.

Важным источником с позиции ценностных оснований семейной жизни является содержание указа Петра I о дифференциации недвижимого имущества на родовое и благоприобретенное (выслуженное, купленное), определившего объем прав и обязанностей его обладателей. Стремление законодателя укрепить наследственные права рода в целом и сохранить монолитность родового земельного фонда выражалось в ограничении распоряжения землей [11, с. 138]. Об этом свидетельствуют нормативные акты, в которых утверждался приоритет мужчины в сфере наследования как носителя родового начала [11, с. 160-173]. Внимание к родовой вотчине можно объяснить и пониманием со стороны власти значимости такой ценностной составляющей семейной жизни, как кровное родство.
Отдельной сферой регулирования семейных отношений выступала статусно-ролевая позиция членов семьи. Статус в семье и связанная с ним совокупность прав и обязанностей изначально являлись нравственным аспектом реализуемой в семье роли. Для определения семейного статуса в нормативных актах используются следующие категории: муж, жена, супруги, отец, мать, родители, дети. Если понятия «муж», «жена», «супруг» в большей степени охватывали сферу интимных отношений и были сопряжены с категорией «брак», то понятия «отец», «мать», «родители», «дети» наполняли ценностную сферу, связанную с самим основанием брачного союза и созданием семьи в полном значении данного слова.

Анализ законодательных документов в отношении вопроса разграничения прав и обязанностей отца и матери позволяет сделать ряд важных выводов. Прежде всего, сама процедура разграничения прав была связана, с одной стороны, с наличием у законодателя представления о воспитательном идеале, а с другой - со степенью авторитетности каждого родителя в отдельности (отец, мать) и совместно (родители) как важной составляющей успешности воспитания. Уже Устав Князя Ярослава предусматривал в ст. 2 ответственность родителей за «приготовление детей к полезной деятельности»: сыновей - к определению на службу, дочерей - к замужеству. Невыдача дочерей замуж каралась штрафом в пользу митрополита [8, с. 168].

С термином «родители», законодательно закрепившимся в период становления централизованного государства, была связана важнейшая духовная категория семейного воспитания - авторитет родительской власти, основывающийся на «естественной зависимости детей от родителей» [3, с. 277]. Глубокое уважение, почтительное отношение, благоговение перед ними - те нравственные качества, которые ввели в терминологию русской семьи понятие «пиетет», подразумевающий в отношении подчинения младших старшим «внутреннюю свободную подчиненность, а не внешнюю принудительность повиновения» [1, с. 535]. Авторитет родительской власти был сильным вплоть до второй половины XIX в., о чем свидетельствует, например, название статьи в законодательных документах того времени «О власти родительской» [11].

Усиление авторитета родительской власти относится к XVI в. Попытка ее ограничения в петровские времена («непринуждение 
к брачному сочетанию») не уменьшала ее значимости. Брак, заключенный без родительского согласия, хотя и признавался действительным, но лишал детей права наследования недвижимого имущества по закону в случае их непрощения родителями. Значение авторитета родительской власти проявилось и в праве родителей применять публично-правовые меры наказания к детям, не повинующимся им или ведущим развратную жизнь.

Несмотря на то, что под категорией «родители» законодателем понимался союз отца и матери в деле воспитания ребенка, акцент делался именно на отце, высокий авторитет которого изначально поддерживался в документах, содержащих нормы семейного права. Так, в упомянутой статье «О власти родительской» в случае споров между родителями, ситуации представления интересов ребенка в суде и т. д. отцу отводится право решающего голоса [11]. Появление ранних законодательных актов XVI в., намечающих пути решения вышеупомянутых вопросов, было обусловлено социально-экономическими и политическими реформами, повлиявшими на правовой статус семьи с позиции переоценки супружеских ролей. Сформировался новый стиль взаимоотношений как взрослых и детей, так и родителей между собой. Это привело к возникновению новых ролевых ожиданий: статус отца-патриарха был сопоставим со статусом государя-патриарха.

На протяжении всей рассматриваемой истории российского законодательства особое внимание уделялось вопросам, связанным с правовым положением ребенка в семье. В ходе анализа содержания законодательных актов складывается представление о полной зависимости детей от родителей, почти бесконтрольном (вплоть до конца
XVII в.) праве наказания последними своего ребенка, что поддерживалось многовековым обычаем непререкаемого авторитета взрослых. Государство и церковь, не предлагая новых правовых форм взаимоотношений между родителями и детьми, кроме безоговорочного послушания, в то же время отстаивали интересы ребенка. Это находило отражение, прежде всего, в законодательном закреплении обязанности обоих супругов содержать и воспитывать детей, введении систем опекунства и наследования по завещанию. В эпоху царствования Екатерины II с зарождением демографии была реализована система мероприятий, направленных на увеличение рождаемости и формирование общественного мнения о высоком социальном статусе многодетной семьи, что подкреплялось, в частности, Указом 1787 г. о процедуре представления кандидатов к некоторым выборным государственным должностям, где особо подчеркивался приоритет женатого человека, имеющего детей [7, т. XXII, № 16603, C. 975].

В целом право до второй половины XIX в. отражало ценности национального характера в общем понятии брачного союза. Укрепление государственного строя с опорой на позиции христианства оказывало влияние на структуру и состав семьи, придавая ей статус культурной подсистемы общества.

Анализ российского законодательства в сфере брачного союза и семейных отношений, а также изучение особенностей воспитания детей в крестьянской семье [2] позволяют обобщить ценности семейного воспитания, которые в процессе своего формирования обеспечивали необходимый уровень стабильного функционирования семьи как социального института, ориентированного на интересы и традиции общества.

Ценности семейного воспитания в России до второй половины XIX в.

\begin{tabular}{|c|c|}
\hline Ценности-цели & $\begin{array}{c}\text { Ценности-средства } \\
\text { нравственные качества-ценности }\end{array}$ \\
\hline 1 & 2 \\
\hline Кровное родство (единоначалие) & $\begin{array}{l}\text { Почитание предков, признательность и благодарность } \\
\text { предкам, гордость за принадлежность к своему роду, зна- } \\
\text { ние своей генеалогии }\end{array}$ \\
\hline $\begin{array}{l}\text { Ребенок (смысл и высокое назначение се- } \\
\text { мьи) }\end{array}$ & $\begin{array}{l}\text { Прилежание, почтение родителей, ответственность за их } \\
\text { старость, воспитание в ребенке чувства собственного до- } \\
\text { стоинства, личностных идеалов, самодеятельности, иници- } \\
\text { ативности. }\end{array}$ \\
\hline $\begin{array}{l}\text { Детство (сензитивный период становления } \\
\text { человека как личности) }\end{array}$ & $\begin{array}{l}\text { Ответственное отношение родителей к периоду детства, } \\
\text { проявляющееся в обеспечении условий для сознательного } \\
\text { понимания детьми себя как личности. }\end{array}$ \\
\hline $\begin{array}{l}\text { Совершеннолетие детей (правоспособ- } \\
\text { ность) }\end{array}$ & $\begin{array}{l}\text { Осознанная готовность, способность к самостоятельной } \\
\text { жизни. }\end{array}$ \\
\hline
\end{tabular}




\begin{tabular}{|c|c|}
\hline 1 & 2 \\
\hline Родители (источник продолжения рода) & $\begin{array}{l}\text { Ответственность перед ребенком за его жизнь, настоящую } \\
\text { и будущую. }\end{array}$ \\
\hline Мать (духовная настоятельница) & $\begin{array}{l}\text { Доброта, нежность, заботливость, мудрость, справедли- } \\
\text { вость, предупредительность, терпение. }\end{array}$ \\
\hline Материнство (достоинство матери) & $\begin{array}{l}\text { Способность к воспитанию ребенка, педагогическая куль- } \\
\text { тура. }\end{array}$ \\
\hline Отец (прародитель) & $\begin{array}{l}\text { Ответственность за семью, мудрость, опытность, разум- } \\
\text { ность проницательность. }\end{array}$ \\
\hline $\begin{array}{l}\text { Отцовство (кормилец, защитник, покрови- } \\
\text { тель) }\end{array}$ & $\begin{array}{l}\text { Способность к воспитанию и содержанию ребенка, педаго- } \\
\text { гическая культура }\end{array}$ \\
\hline $\begin{array}{l}\text { Родительский авторитет (нравственная зна- } \\
\text { чимость в глазах детей) }\end{array}$ & отношении всех чле- \\
\hline $\begin{array}{l}\text { Родительство (нравственная зрелость в от- } \\
\text { ношении деторождения) }\end{array}$ & $\begin{array}{l}\text { Понимание значимости предназначения семейной жизни, } \\
\text { потребность в детях, ответственность за деторождение } \\
\text { перед родом, государством и церковью. }\end{array}$ \\
\hline $\begin{array}{l}\text { Воспитание (процесс формирования духов- } \\
\text { но-нравственной основы личности) }\end{array}$ & Сознательность, просвещенность в вопросах воспитания. \\
\hline $\begin{array}{l}\text { Родительское благословение (потенциаль- } \\
\text { ная сила для достижения благополучия, } \\
\text { успешности) }\end{array}$ & келание доб \\
\hline Родительское наставление (поучение, наказ) & Тность \\
\hline $\begin{array}{l}\text { Kpec } \\
\text { Kpec }\end{array}$ & $\begin{array}{l}\text { Пра } \\
\text { Отв }\end{array}$ \\
\hline $\begin{array}{l}\text { ная чета, единство ду } \\
\text { о) }\end{array}$ & Умение сопереживать. \\
\hline Муж (домовладыка, защитник, советчик) & $\begin{array}{l}\text { Быть достойным уважения, способность к хозяйственно- } \\
\text { распорядительной деятельности, твердость воли, социаль- } \\
\text { ная активность. }\end{array}$ \\
\hline путница ж & $\begin{array}{l}\text { Привлекательность, чуткость, способность к хозяйственно-- } \\
\text { экономической деятельности, добродетельность, деловой } \\
\text { партнер }\end{array}$ \\
\hline Дом & $\begin{array}{l}\text { Теплота, гостеприимство, дружелюбие, доброжелатель- } \\
\text { ность, чистоплотность, хлебосольство, радушие, щедрость, } \\
\text { услужливость, домовитость. }\end{array}$ \\
\hline $\begin{array}{l}\text { Семейный лад (единение, внутренняя согла- } \\
\text { сованность) }\end{array}$ & $\begin{array}{l}\text { Уважительность друг к другу, почтительность, послуш- } \\
\text { ность, приноравливание, уступчивость. }\end{array}$ \\
\hline $\begin{array}{l}\text { Семейный совет (совместное обсуждение, } \\
\text { коллегиальность) }\end{array}$ & $\begin{array}{l}\text { Уважительное отношение к мнению члена семьи, справед- } \\
\text { ливость в оценке мнения, равнозначность каждого }\end{array}$ \\
\hline $\begin{array}{l}\text { Венчание (нравственный договор брачую- } \\
\text { щихся для совместной жизни, рождения и } \\
\text { воспитания детей) }\end{array}$ & $\begin{array}{l}\text { Взаимная верность, целомудренность в отношениях, пред- } \\
\text { шествующих браку }\end{array}$ \\
\hline Брак (духовно-нравственный союз) & $\begin{array}{l}\text { Моральная ответственность друг перед другом, физиоло- } \\
\text { гическая и нравственная зрелость как готовность к всту- } \\
\text { плению в брак. }\end{array}$ \\
\hline $\begin{array}{l}\text { Кровное свойство (породненность двух ро- } \\
\text { дов в результате брака, сватовство) }\end{array}$ & $\begin{array}{l}\text { Доброжелательность, желание прийти на помощь в трудной } \\
\text { жизненной ситуации. }\end{array}$ \\
\hline Любовь (взаимное душевное проникновение) & $\begin{array}{l}\text { Заботливость, доверительность, жалостливость, искрен- } \\
\text { ность. }\end{array}$ \\
\hline Целомудрие (чистота ду & Скромность, стыдливость \\
\hline
\end{tabular}

Осмысление с позиции педагогической науки национальных приоритетов государства в сфере брачно-семейных отношений, исторически являющихся ценностной доминантой семейной жизни, позволяет конкретизировать вопрос о ведущем факторе его позитивного развития в современных условиях. Несомненно, это семья, культурное состояние которой определяет культурное состояние государства и общества. В рамках реализации приоритетных национальных проектов должны приниматься и реализовываться такие программы развития образовательной и демографической политики, в основу которых положен анализ ценностей семейного воспитания, ставших традиционными. В ситуации высокой информационной доступности альтернативных точек зрения на феномен семьи в качестве жизненного приоритета для отечественной культуры современной молодежи следует определить традиционные семейные ценности.

\section{СПИСОК ЛИТЕРАТУРЫ}

1. Владимирский-Буданов, М. Ф. Обзор истории русского права / М. Ф. Владимирский-Буданов. - Москва : Территория будущего, 2005. - 800 с. - ISBN 978-5-7333-0172-4. 
2. Володина, Л. О. Ценности воспитания в русской крестьянской семье во второй половине XIX - начале XX века : диссертация на соискание ученой степени доктора педагогических наук / Л. О. Володина. - Москва, 2017. - 388 с. 3. Загоровский, А. И. Курс семейного права / А. И. Загоровский. - Одесса : Экономическая типография, 1902. $460 \mathrm{c}$.

4. Неволин, К. А. История российских гражданских законов : в 3 т. Т. 1 : Введение и книга первая о союзах семейственных / К. А. Неволин. - Санкт-Петербург : Тип. Императорской Академии наук, 1851. - 456 с.

5. Новый памятник законов Империи Российской : в 9 т. Т. 4. - Санкт-Петербург : Типография Правительствующего Сената, 1826. - $560 \mathrm{c}$.

6. Павлов, А. С. Курс церковного права / А. С. Павлов. - Санкт-Петербург : Лань, 2002. - 384 с. - ISBN 5-8114-0434-4. 7. Полное собрание законов Российской Империи с 1649 г. (ПСЗРИ) : в 45 т. URL: http://www.nlr.ru/e-res/law r/ search.php (дата обращения: 01.07.2019).

8. Российское законодательство X-XX вв. : в 9 т. Т. 1. Законодательство Древней Руси / ответственный редактор В. Л. Янин. - Москва : Юридическая литература, 1984. - 432 с. - ISBN 5-7260-0009-9.

9. Российское законодательство X-XX вв. : в 9 т. Т. 2. Законодательство периода образования и укрепления Русского централизованного государства / ответственный редактор А. Д. Горский. - Москва : Юридическая литература, 1985. - 520 с. - ISBN 5-7260-0009-9.

10. Российское законодательство X-XX вв. : в 9 т. Т. 4. Законодательство периода становления абсолютизма / ответственный редактор А. Г. Маньков. - Москва : Юридическая литертаура, 1986. - 512 с. - ISBN 5-7260-0009-9.

11. Собрание законов Российской Империи, повелением государя императора Николая Павловича составленное : в 16 т. T. 10 : Свод законов гражданских. Свод законов межевых. URL: http://pravo.gov.ru/proxy/ips/?empire\&nochache (дата обращения: 01.07.2019).

12. Стоюнин, В. Я. Наша семья и ее исторические судьбы / В. Я. Стоюнин // Педагогические сочинения. - СанктПетербург ; Москва : Типография Стасюлевича, 1903. - С. 1-90.

\section{REFERENCES}

1. Vladimirskij-Budanov M. F. Obzor istorii russkogo prava [Overview of the history of Russian law]. Moscow, 2005. 800 p. (In Russ.).

2. Volodina L. O. Cennosti vospitaniya v russkoj krest'yanskoj sem'e vo vtoroj polovine XIX - nachale XX veka. Diss. dokt. ped. nauk [The values of upbringing in a Russian peasant family in the second half of the XIX - early XX centuries. Diss. Dsc. in Pedagogy]. Moscow, 2017. 388 p. (In Russ.).

3. Zagorovskij A. I. Kurs semejnogo prava [Family Law Course]. Odessa, 1902. 460 p. (In Russ.).

4. Nevolin K. A. Istoriya rossijskih grazhdanskih zakonov v 3 t. T. 1. Vvedenie i kniga pervaya o soyuzah semejstvennyh [The history of Russian civil laws in 3 vol. Vol. 1. Introduction and the first book on family unions]. St. Petersburg, 1851. 456 p. (In Russ.).

5. Novyj pamyatnik zakonov Imperii Rossijskoj v 9 t. T. 4. [A new monument to the laws of the Russian Empire in 9 vol. Vol. 4]. St. Petersburg, 1826. 560 p. (In Russ.).

6. Pavlov A. S. Kurs cerkovnogo prava [Church Law Course]. St. Petersburg, 2002. 384 p. (In Russ.).

7. Polnoe sobranie zakonov Rossijskoj Imperii s $1649 \mathrm{~g}$. (PSZRI) v $45 \mathrm{t}$. [The complete collection of laws of the Russian Empire since 1649 in 45 vol.]. Available at: http://www.nlr.ru/e-res/law_r/search.php ( accessed 01.07.2019). (In Russ.). 8. YAnin V. L. (red.) Rossijskoe zakonodatel'stvo X-XX vv. v9 t. T. 1. Zakonodatel'stvo Drevnej Rusi [Russian legislation of the 10th-20th centuries in 9 vol. Vol. 1. Legislation of Ancient Russia]. Moscow, 1984. 432 p. (In Russ.).

9. Gorskij A. D. (red.) Rossijskoe zakonodatel'stvo X-XX vv. v9 t. T. 2. Zakonodatel'stvo perioda obrazovaniya i ukrepleniya Russkogo centralizovannogo gosudarstva [Russian legislation of the 10th-20th centuries in 9 vol. Vol. 2. Legislation of the period of formation and strengthening of the Russian centralized state]. Moscow, 1985. 520 p. (In Russ.).

10. Man'kov A. G. (red.) Rossijskoe zakonodatel'stvo X-XXvv. v9t. T. 4. Zakonodatel'stvo perioda stanovleniya absolyutizma [Russian legislation of the 10th-20th centuries in 9 vol. Vol. 4. Legislation of the period of absolutism]. Moscow, 1986. 512 p. (In Russ.).

11. Sobranie zakonov Rossijskoj Imperii, poveleniem gosudarya imperatora Nikolaya Pavlovicha sostavlennoe v 16 t. T. 10. Svod zakonov grazhdanskih. Svod zakonov mezhevyh [The collection of laws of the Russian Empire by order of the Emperor Nikolai Pavlovich compiled in 16 vol. Vol. 10. Code of civil laws. Code of laws of boundary]. Available at: http://pravo.gov.ru/ proxy/ips/?empire\&nochache ( accessed 01.07.2019). (In Russ.).

12. Stoyunin V. YA. Nasha sem'ya i ee istoricheskie sud'by [Our family and its historical destinies]. Pedagogicheskie sochineniya [Pedagogical works]. Saint Petersburg, Moscow, 1903, pp. 1-90. (In Russ.). 